\title{
Effect of Growth Regulators and Ethanol on Termination of Dormancy in Potato Tubers
}

\author{
Slawomir Wróbel ${ }^{1,2}$ • Jacek Kęsy ${ }^{3} \cdot \operatorname{Krzysztof~Treder~}^{1}$ (D)
}

Published online: 20 June 2017

(C) The Author(s) 2017. This article is an open access publication

\begin{abstract}
The main objective of this study was to find the best practice of inducing the sprouting of dormant potato tubers. We compared two protocols of breakage of dormancy, which are based on dipping excised potato eyes in an aqueous solution of gibberellic acid $\left(\mathrm{GA}_{3}\right)$ and kinetin (standard 1) or in the aqueous solution of $\mathrm{GA}_{3}$, thiourea, and daminozide (standard 2 ), with a newly reported approach based on ethanol. We tested the effect of ethanol alone or in combination with $\mathrm{GA}_{3}$ and/or kinetin on dormancy release and sprouting of the potato tubers. As a model, we used two potato genotypes (cultivars Pasat and Dorota), with long dormancy of 5 and 10 weeks respectively. We showed that the standard 2 was the most effective treatment both for dormancy breaking and in promoting sprout growth, especially for cv. Dorota, for which the treatment induced $82.3 \%$ of tuber eye-plugs to sprout 28 days after treatment and to produce $93.2 \%$ of emerged plants after subsequent 28 days of cultivation in the greenhouse. For this cultivar, similar efficacy was observed for the combination of $4 \%$ ethanol with $\mathrm{GA}_{3}$ and kinetin. The
\end{abstract}

Krzysztof Treder

k.treder@ihar.edu.pl

Sławomir Wróbel

wrobel@ziemniak-bonin.pl; swrobel@europlant.biz

Jacek Kęsy

kesy@umk.pl

1 Plant Breeding and Acclimatization Institute - National Research Institute, Bonin Research Center, 76-009 Bonin 3, Bonin, Poland

2 Present address: Europlant Handel Ziemniakami Sp. z o.o, Laski Koszalińskie 3a, 76-039 Biesiekierz, Poland

3 Faculty of Biology and Environment Protection, Chair of Plant Physiology and Biotechnology, Nicolaus Copernicus University, Lwowska 1, 87-100 Torun, Poland same concentration of ethanol combined with $\mathrm{GA}_{3}$ but without kinetin was the most efficient treatment for breaking dormancy of cultivar Pasat. However, the difference between the various treatment combinations was statistically insignificant. Ethanol alone or in combination with kinetin poorly induced breakage of dormancy, confirming the main role of $\mathrm{GA}_{3}$ in artificial dormancy breaking. Thus our study showed that the standard 2 is the most effective approach for breakage of dormancy at least with long term-dormancy cultivars.

Resumen El principal objetivo de este estudio fue encontrar la mejor práctica para inducir la brotación en tubérculos de papa en dormancia. Comparamos dos protocolos para romper la dormancia, basados en inmersión de yemas (ojos) aislados del tubérculo, en una solución acuosa de ácido giberélico (GA3) y cinetina (estándar 1), o en una solución acuosa de GA3, tiourea, y daminozida (estándar 2), con un nuevo enfoque reportado basado en etanol. Probamos el efecto del etanol solo o en combinación con GA3 y/o cinetina en la liberación de la dormancia y en la brotación de los tubérculos de papa. Como modelo usamos dos genotipos de papa (variedades Pasat y Dorota), con dormancia larga de 5 y 10 semanas, respectivamente. Mostramos que el estándar 2 fue el tratamiento más efectivo tanto para romper la dormancia como para promover el crecimiento del brote, especialmente para la variedad Dorota, para la cual el tratamiento indujo un $82.3 \%$ de los ojos del tubérculo a brotar 28 días después del tratamiento, y a producir $93.2 \%$ de plantas emergidas después de 28 días subsecuentes de cultivo en invernadero. Para esta variedad se observó eficacia similar con la combinación de $4 \%$ de etanol con GA3 y cinetina. La misma concentración de etanol en combinación con GA3, pero sin cinetina, fue el tratamiento más eficiente para romper la dormancia de la variedad Pasat. No obstante, la diferencia entre las diversas combinaciones de tratamientos fue insignificante 
estadísticamente. El etanol solo o en combinación con cinetina indujo pobremente el rompimiento de la dormancia, confirmando el principal papel de GA3 en el rompimiento artificial de la dormancia. De aquí que nuestro estudio mostró que el estándar 2 es el enfoque más efectivo para el rompimiento de la dormancia por lo menos con variedades de dormancia larga.

Keywords Abscisic acid · Daminozide - Gibberellic acid . Kinetin $\cdot$ Thiourea $\cdot$ Seed potato $\cdot$ Sprouting

\section{Introduction}

Even under optimal conditions for growth, freshly harvested tubers do not sprout as they require a rest period or dormancy, which can vary depending on the cultivars. The beginning of dormancy coincides with the tuber initiation on the stolons. The depth of dormancy is not constant during dormancy. Its intensity gradually increases and after the haulm removal, it rapidly reaches a maximum. After harvest, the dormancy intensity decreases and at certain time (usually 1-3 months) tubers show apical dominance, only one eye on the tuber develops a sprout. After longer storage, the apical dominance diminishes and multiple sprouts appear along the tuber. For practical reasons, the duration of dormancy can be defined as the time between harvest and formation of sprouts, which reach at least $2 \mathrm{~mm}$ in height on $80 \%$ of tested tubers (Struik and Wiersema 1999). The duration and depth of dormancy are influenced to some extent by pre-harvest growing conditions and post-harvest storage conditions, but both depend primarily on the potato genotype (Ranalli et al. 1994; Zarzyńska 2004; Andrenelli et al. 2005; Wróbel 2008; Wróbel and Robak 2009; Bamberg 2010, 2014; Wróbel and Robak 2014).

The ability to control of dormancy is essential to all segments of the potato industry. Usually delayed sprouting is wanted to prolong tuber storage. The tubers are either stored at low temperatures $\left(2-4{ }^{\circ} \mathrm{C}\right)$ or treated with synthetic sprouting inhibitors (Struik and Wiersema 1999; Wiltshire and Cobb 1996). However, during seed multiplication programs and for rapid post-harvest disease testing, elimination or significant shortening of dormancy is often needed. Premature sprout growth can be induced by chemical, hormonal or physical treatments. Depending on the application time, these treatments can artificially break tuber dormancy or stimulate the growth of sprouts in tubers, whose dormancy has naturally ended. Various chemicals including ethyl bromide, rindite, ethylene chlorohydrin, carbon disulfide, are effective but impose danger to humans and to the environment (Coleman 1984; Struik and Wiersema 1999; Akoumianakis et al. 2000). Other, like thiourea (Struik and Wiersema 1999) or cytokinins (Hemberg 1970; Suttle 2008) are effective only in the later stages of dormancy when its depth is lower. An initial period of tuber resistance to artificial dormancy break can be reduced, but not eliminated by synthetic phenylurea or nitroguanidine cytokinins (Suttle 2008).

Early storage dormancy can be broken with exogenous gibberellins (GAs), typically with gibberellic acid $\left(\mathrm{GA}_{3}\right)$ (Choudhuri and Ghose 1963; Bruinsma et al. 1967; Struik and Wiersema 1999; Alexopoulos et al. 2008; Hartmann et al. 2011; Jansky and Hamernik 2015). $\mathrm{GA}_{3}$ is the most effective on cut tubers. Cutting alone may also break or shorten dormancy (Struik and Wiersema 1999) but the addition of $\mathrm{GA}_{3}$ significantly enhances the effect (Bruinsma et al. 1967; Jansky and Hamernik 2015). GA 3 promotes sprouting and increases the number of sprouts per tuber. At higher concentrations, $\mathrm{GA}_{3}$ induces the formation of elongated sprouts, morphologically abnormal plants and deformed tubers (Choudhuri and Ghose 1963; Struik and Wiersema 1999). These negative effects can be suppressed by simultaneous or subsequent treatment of the eye-plugs with daminozide (Bruinsma et al. 1967). One of the limitations in the chemical-induced breakage of dormancy is that cultivars vary in their response to artificial dormancy breaking. The inability to precisely define the physiological age of tubers or the depth of their dormancy can lead to inadequate timing of treatment and may result in poor sprouting. This is a common issue reported when using the aqueous solution of $\mathrm{GA}_{3}$ and kinetin to sprout eye-plugs from immature tubers as experienced by the Polish Plant Health and Seed Inspection Services in seed certification trials for pathogen testing. To adjust the time of treatment to particular genotypes, Wróbel (Wróbel 2008; Wróbel and Robak 2011, 2014) investigated the relationship between duration of storage period and sprouting of potato cultivars after artificial dormancy breaking. Cultivars were grouped based on whether they (i) could be treated immediately after harvest, (ii) require 5-weeks or (iii) 10-weeks of storage before breaking dormancy. The eye-plugs were dipped in the water solution of $\mathrm{GA}_{3}$, thiourea and daminozide (Wróbel 2008; Wróbel and Robak 2011, 2014). The result showed that the time of effective treatment did not correlate with the natural dormancy duration or maturity group of the investigated genotypes (Wróbel and Robak 2014).

Recently, it was reported that ethanol in combination with sucrose rapidly breaks dormancy of in vitro-cultured growing and maturing tubers. The fate of growing bud was modulated by sucrose concentration. With $1 \%$ sucrose, the growth of sprout was observed, while with an increased concentration of $8 \%$, secondary and tertiary tubers were formed (Claassens et al. 2005). However, the effect of ethanol on dormancy of field-grown tubers was not investigated.

Here we compared the protocol of the $\mathrm{GA}_{3}$, thiourea and daminozide solution (standard 2) to the routinely used $\mathrm{GA}_{3}$ and kinetin treatment (standard 1) by Polish Plant Health and Seed Inspection Services and to the ethanol treatment, on the breakage of dormancy and induction of sprouting of two cultivars, Pasat (Wróbel 2008) and Dorota (Wróbel and Robak 
2011) with different deep dormancy stages. None of the treatments were as effective in dormancy breaking as standard 2, although the combination of $4 \%$ ethanol with $\mathrm{GA}_{3}$ and kinetin had a similar efficacy.

\section{Material and Methods}

\section{Plant Material}

Two potato cultivars (Solanum tuberosum): Pasat (mid-early, starchy) and Dorota (early, starchy) were used in these studies. Both cultivars have a long stage of deep dormancy, of 5 weeks (Wróbel 2008) and 10 weeks (Wróbel and Robak 2011) respectively. Certified, disease free potato tubers were planted the last week of April 2011-2012 and harvested before the physiological end of the vegetative propagation period, during the first week of August (cv. Dorota) and mid-August (cv. Pasat). The area of land used for cultivation of each cultivar was $120 \mathrm{~m}^{2}$ and the number of planted tubers was 550 in each plot. After harvest, tubers were stored for one day at room temperature before testing. Dormancy breaking experiments were started the second day after harvest.

\section{Chemicals}

Gibberellin (GA) and kinetin were purchased from Alfa Aesar $\mathrm{GmbH}$, organic solvents for extraction and chromatographic analysis were supplied by Sigma-Aldrich Co. B-Nine 85 SG is a commercial product containing $850 \mathrm{~g} \cdot \mathrm{kg}^{-1}$ of daminozide. For the preparation of solutions and tuber rinsing, deionized water with a conductivity of $0.06 \mu \mathrm{S} \cdot \mathrm{cm}^{-1}$ was used.

\section{Sprout Growth Assay}

The effect of tested solutions on dormancy breaking and subsequent sprouting was investigated on tubers harvested two days before treatment. Spherical tuber slices (eye-plugs, diameter about $1.8 \mathrm{~cm}$ ) were excised from the tubers, using a hemispherical spoon, designed for the grow-out test. Two samples, each containing a single eye, were scooped from each tuber. One of the samples was later evaluated visually for growth response, while the second was examined for the level of abscisic acid (ABA). Cuttings, prepared for evaluation of growth reaction, were either immersed for $10 \mathrm{~min}$ in the solution containing GA and kinetin at the concentration of $1 \mathrm{mg} \cdot \mathrm{L}^{-1}$ (standard 1) or in the solution containing $1 \mathrm{mg} \cdot \mathrm{L}^{-} 1 \mathrm{GA}$, $10 \mathrm{~g} \cdot \mathrm{L}^{-} 1$ thiourea and $3 \mathrm{~g} \cdot \mathrm{L}^{-1}$ B-Nine $85 \mathrm{SG}$ (standard 2). Standard 1 is recommended in the official procedure used by the Polish Plant Health and Seed Inspection Services for dormancy breaking during the grow-out test, performed to certify health status of seed tubers. Standard 2, used for many years in the Department of Potato Protection and Seed Science in Bonin, has never been compared to other protocols.

To test ethanol ability to overcome dormancy, cuttings prepared as above were immersed in $1 \%$ sucrose with $0.5,1,2$, or $4 \%$ ethanol or in the same solutions of ethanol and sucrose with the addition of $1 \mathrm{mg} \cdot \mathrm{L}^{-1}$ of GA or $1 \mathrm{mg} \cdot \mathrm{L}^{-1}$ of kinetin or both and soaked for 15 or $30 \mathrm{~min}$ (32 variants). The above sucrose concentration was applied to ensure that treatment will induce sprouting (Claassens et al. 2005). Control samples were soaked for $15 \mathrm{~min}$ in water.

After dipping, the eye-plugs were washed in water and stored on moist peat at conditions which favor the sprouting of buds (dark, $21 \pm 1{ }^{\circ} \mathrm{C}, 85 \pm 5 \% \mathrm{RH}$ ). The number of sprouted eye-plugs and sprout length were measured starting from the 7th day after treatment (dat.) every 3-4 days for 28 days. Dormancy was considered to be broken once a sprout of minimum length $2 \mathrm{~mm}$ had formed (Struik and Wiersema 1999; Wróbel 2008).

To determine the effect of treatments on plant emergence, once sprout growth assay was terminated (28 dat.), eye-plugs were planted into pots filled with peat substrate and placed in a greenhouse or a growth chamber. Emergence and growth of the offspring plants were recorded every 3-4 days for 28 days.

The study was conducted during two growing seasons (2011 and 2012). Each year, all experiments were conducted independently three times, with 20 tuber cuttings per replication. If not indicated otherwise, data shown in figures and tables represents 2-years averages.

\section{Determination of Endogenous ABA}

For every 20 tuber cuttings intended for ABA content examination, 5 cuttings were randomly selected and stored at a temperature of $-80^{\circ} \mathrm{C}$. The remaining 15 were placed on moist peat and planted in the dark at $21 \pm 1{ }^{\circ} \mathrm{C}$ and $85 \pm 5 \%$ RH. After 28 days of planting, the next five were selected from these 15 cuttings, and similarly frozen at $-80^{\circ} \mathrm{C}$.

ABA content was analyzed in samples representing four treatments of each cultivar, selected on the basis of the observed efficiency in dormancy breaking. Additionally, control treatment with water was also analyzed.

Analyses of ABA were carried out as described in the minor modification to the GC-MS method by Wilmowicz et al. (2008). For this purpose, the five frozen tuber cuttings for each individual sample were additionally frozen in liquid nitrogen, then wrapped together in aluminum foil, crushed with a hammer and triturated in a mortar. For analysis, approximately $2 \mathrm{~g}$ of powdered material was used.

Free ABA was extracted with $80 \%(v / v)$ methanol in two parts of $20 \mathrm{~mL}$ each. $\left[6-{ }^{2} \mathrm{H}_{3}\right] \mathrm{ABA}(100 \mathrm{ng})$ was added to the extract as an internal standard. The suspension was left overnight to stir and then centrifuged at $10,000 \times \mathrm{g}$ for $10 \mathrm{~min}$ per sample. Combined extracts were reduced to the aqueous 
phase, acidified with $12 \mathrm{M} \mathrm{HCl}$ to $\mathrm{pH} 2.0$ and centrifuged at $10,000 \times \mathrm{g}$ for $15 \mathrm{~min}$. The supernatant was partitioned three times against ethyl acetate and dried in a vacuum. The residue was dissolved in $3 \mathrm{~mL}$ of $20 \%$ isopropanol, the $\mathrm{pH}$ was adjusted to approximately 7 and then applied to a DEAE Sephadex A25 SPE column (Sigma-Aldrich Co.), $3 \mathrm{~mL}$, the acetate form equilibrated to $\mathrm{pH} 7$. The column was washed twice with $4 \mathrm{~mL}$ of $20 \%$ isopropanol and then ABA was eluted with $6 \mathrm{~mL}$ of $5 \%(\mathrm{v} / \mathrm{v})$ acetic acid and $50 \%$ isopropanol. The eluate was evaporated and further purified by HPLC using the SUPELCOSIL ABZ + PLUS column $(250 \times 4.5 \mathrm{~mm}, 5 \mu \mathrm{m}$ particle size; Supelco Inc., USA). The samples were dissolved in $200 \mu \mathrm{L}$ of $20 \%$ methanol and chromatographed with a linear gradient of 20 to $80 \%$ methanol in $1 \%(\mathrm{v} / \mathrm{v})$ formic acid for $20 \mathrm{~min}$., flow rate $1.0 \mathrm{~mL} / \mathrm{min}$. at a temperature of $22{ }^{\circ} \mathrm{C}$. The fractions collected after $12.5 \pm 0.5 \mathrm{~min}$. Were evaporated to dryness, methylated with diazomethane, dissolved in $20 \mu \mathrm{L}$ of methanol and analysed using a GC-MS-SIM (Auto-System XL coupled to a Turbo Mass, Perkin Elmer, USA) and using a MDN-5 column $(30 \mathrm{~m} \times 0.25 \mathrm{~mm}, 0.25 \mu \mathrm{m}$ phase thickness, Supelco Inc., USA). The GC temperature program was $120^{\circ} \mathrm{C}$ for $1 \mathrm{~min}, 120-250{ }^{\circ} \mathrm{C}$ at $10{ }^{\circ} \mathrm{C} / \mathrm{min}$, with a flow rate of $1.5 \mathrm{~mL} \cdot \mathrm{min}^{-1}$, the injection port was $280{ }^{\circ} \mathrm{C}$, and the electron potential $70 \mathrm{eV}$. The retention times of $\mathrm{ABA}$ and $\left[6-{ }^{2} \mathrm{H}_{3}\right] \mathrm{ABA}$ were 14.07 and $14.3 \mathrm{~min}$ respectively. GC/MS-SIM was performed by monitoring m/z 162, 190 for endogenous ABA and 166,194 for $\left[6-{ }^{2} \mathrm{H}_{3}\right] \mathrm{ABA}$, taking into account the appropriate correction factors.

\section{Statistical Analysis}

In order to normalize data, the obtained percentages of sprouted eye-plugs were transformed according to the following formula (Wójcik et al. 1976):

$$
\begin{aligned}
& y=\arcsin \sqrt{x} \\
& \quad \frac{\text { in which }}{\mathrm{y}} \quad \text { value after transformation } \\
& \mathrm{x} \text { percentage values }
\end{aligned}
$$

Subsequently, the obtained values were subjected to an analysis of variance (ANOVA). To assess the significance of differences between the studied variants, mean values were tested using Tukey's test, setting an alpha level of $\alpha=0.01$ in order to increase the reliability of the obtained results. The Pearson correlation coefficients between the tuber cuttings sprouting, and their subsequent growth in the soil conditions was also calculated. Statistical calculations were carried out using the statistical software package Statistica 10.0 (StatSoftInc). The obtained statistical results were transformed to percentages and are presented in this form. The data were plotted using GraphPad Prism 6 (GraphPad Sofware, San Diego, CA, USA).

\section{Results}

\section{Influence of Varietal and Seasonal Diversity on Relative Depth of Dormancy}

To determine the relative depth of dormancy of the tested cultivars, eye-plugs from each of the cultivars were excised from tubers and dipped into water. Next, the eye-plugs were stored under the optimal condition for sprouting (dark, $\left.21 \pm 1{ }^{\circ} \mathrm{C}, 85 \pm 5 \% \mathrm{RH}\right)$. Starting from day 7 , the number of sprouted eye-plugs was recorded every 3-4 days during 28 days. The relative depth of dormancy was expressed as a percentage of the sprouting eye-plugs. No difference in the rate of sprouting was observed between the two cultivars Dorota and Pasat until day 13 (Table 2). While the eye-plugs of cv. Dorota remained dormant during the duration of the experiment, the number of sprouted cuttings of cv. Pasat increased up to $20,9 \%$ (Table 2).

To assess the influence of the growing season on the rate of sprouting after artificial dormancy breaking, values from all treatments (Table 1) were averaged (Table 2). A strong effect of the growing season on the depth of tuber dormancy in both Dorota and Pasat cultivars was observed (Table 3). While cv. Dorota was significantly more deeply dormant than cv. Pasat during both growing seasons, dormancy was significantly weaker in 2012 than in 2011 for both cultivars (Table 3).

\section{Comparison of Protocols Based on Standards 1 and 2}

To test the efficacy of different treatments used for breaking dormancy, we compared the effect of the standard $\mathrm{GA}_{3}$ and kinetin treatment (standard 1) used by Polish Plant Health and Seed Inspection Services and our protocol with the $\mathrm{GA}_{3}$, thiourea and daminozide solution (standard 2) on tuber dormancy of cv. Dorota and cv. Pasat. Eye-plugs were soaked in respective mixtures for $10 \mathrm{~min}$. The rate of sprouting was counted every 3-4 days for 28 days and the dates (in dat.) of the maximal and the final number of sprouts were recorded.

Both treatments resulted in the growth of sprouts. However, standard 2 was more effective (Fig. 1). After this treatment intense sprouting was visible for cv. Pasat from 10 dat., $80 \%$ sprouting of the tested tubers was reached at 13 dat. And the highest number of sprouts $(87,7 \%)$ was recorded for this cultivar 24 dat. Eye-plugs of cv. Dorota treated with standard 2 had a much slower rate of sprouting and reached $82 \%$ sprouting at 28 dat. However, under the standard 1 treatment, the first visible sprouts of Dorota appeared only at 16 dat., while the tubers started sprouting at 10 dat. With standard 2 . After standard 1 treatment, the maximum number of sprouts 
Table 1 The composition of solutions used in the study of dormancy release of potato tuber cuttings. The concentrations of $\mathrm{GA}$ and kinetin were $1 \mathrm{mg} \cdot \mathrm{L}^{-1}$, thiourea $-10 \mathrm{~g} \cdot \mathrm{L}^{-1}$ and $\mathrm{B}-\mathrm{Nine}$ $85 \mathrm{SG}-3 \mathrm{~g} \cdot \mathrm{L}^{-1}$ )

\begin{tabular}{lll}
\hline Mix number & Composition & Soaking time [min] \\
\hline K1 & Control - deionized water & 15 \\
K2 & Standard $1-\mathrm{GA}+$ kinetin $)^{\dagger}$ & 10 \\
K3 & Standard $2-\mathrm{GA}+$ thiourea + B-Nine $85 \mathrm{SG}^{\dagger \dagger}$ & 15 \\
K4-K7 & $0.5,1,2$ or $4 \%$ of ethanol $+1 \%$ sucrose & 15 or 30 \\
K8-K11 & $0.5,1,2$ or $4 \%$ of ethanol $+1 \%$ sucrose + GA & 15 or 30 \\
K12-K15 & $0.5,1,2$ or 4\% of ethanol $+1 \%$ sucrose + kinetin & 15 or 30 \\
K16-K19 & $0.5,1,2$ or $4 \%$ of ethanol $+1 \%$ sucrose + GA + kinetin & 15 or 30 \\
\hline
\end{tabular}

${ }^{\dagger}$ the certified method employed by the Polish Plant Health and Seed Inspection Services for dormancy breaking during official supervision of potato seeds health.

${ }^{\dagger \dagger}$ commonly used method for breaking dormancy employed by the Department of Potato Protection and Seed Science in Bonin was reached by both cultivars 28 dat. And it was 70.8 and $43.5 \%$ for cv. Pasat and Dorota, respectively (Fig. 1).

\section{Impact of Ethanol, $\mathbf{G A}_{3}$, and Kinetin on Dormancy Breaking and Subsequent Emergence of Offspring Plants}

We next compared the efficacy of an ethanol-based, $\mathrm{GA}_{3}$ or kinetin treatments in inducing sprouting and plant emergence. We observed that the ethanol treatment induced sprout growth in a dose-dependent manner and a $4 \%$ concentration was the most effective. Limited sprouting was recorded for cv. Dorota, where $4 \%$ ethanol broke the dormancy in $26.4 \%$ eye-plugs. In contrast, cv. Pasat reacted to ethanol with profound sprouting (76.7\% at $4 \%$ ethanol) (Table 4 , sprouting). However, most of the sprouts of cv. Pasat did not grow further, thus the number of emerged plants was just slightly higher for cv. Dorota (Table 4, emergence).

The application of $\mathrm{GA}_{3}$ alone was sufficient to induce successful sprouting of both cultivars. Almost $44 \%$ of cv. Dorota and about $80 \%$ of cv. Pasat has sprouted (Table 5, sprouting). However, in this experiment control eye-plugs of cv. Pasat, treated with water (control) also sprouted quite efficiently.

Table 2 The sprouting ability of potato tuber cuttings of the Dorota and Pasat cultivars in 2011-2012, expressed as an average percentage of sprouted cuttings. The grow-out-test cuttings were soaked for $15 \mathrm{~min}$ in deionized water beforehand

\begin{tabular}{llr}
\hline Observation day & cv. Dorota & cv. Pasat \\
\hline 7 & $0.0 \mathrm{a}$ & $0.0 \mathrm{a}$ \\
10 & $0.0 \mathrm{a}$ & $0.6 \mathrm{a}$ \\
13 & $0.0 \mathrm{~b}$ & $6.8 \mathrm{a}$ \\
16 & $0.3 \mathrm{~b}$ & $13.2 \mathrm{a}$ \\
20 & $0.3 \mathrm{~b}$ & $18.8 \mathrm{a}$ \\
24 & $0.8 \mathrm{~b}$ & $20.2 \mathrm{a}$ \\
28 & $0.8 \mathrm{~b}$ & $20.9 \mathrm{a}$ \\
\hline
\end{tabular}

means within each row with the same letters do not differ significantly according to the Tukey test $(p=0.01)$
Thus, only $20 \%$ of the Pasat sprouts can be accounted to the $\mathrm{GA}_{3}$ treatment. When the eye-plugs were planted in the greenhouse, most sprouts of cv. Dorota continued to grow to offspring plants, while most sprouts of cv. Pasat did not, resulting in a low number of emerged plants (Table 5, emergence).

Kinetin application also affected the number of sprouted eye-plugs but cultivars responded differently to the treatment (Table 6, sprouting). The hormone significantly induced sprouting of cv. Dorota, but the reverse effect was observed for cv. Pasat. Similarly to what was observed with ethanol and $\mathrm{GA}_{3}$ treatments, most sprouts of cv. Pasat ceased to grow, resulting in a low number of emerged plants (Table 5, emergence).

\section{Effect of Ethanol Treatment Duration}

The duration of the treatment had a significant impact on dormancy breaking. Longer dipping (30 min vs. $15 \mathrm{~min}$ ) of eye-plugs profoundly increased the dormancy breaking efficacy (Table 7). For cv. Dorota, the effect was significant

Table 3 The effect of the growing season on the ability to sprout for potato tuber cuttings of the Dorota and Pasat cultivars in 2011 and 2012, expressed as an average percentage of sprouted cuttings. Data comprises the mean values from all treatments

\begin{tabular}{lllllr}
\hline Observation day & \multicolumn{2}{l}{ cv. Dorota } & & \multicolumn{2}{c}{ cv. Pasat } \\
\cline { 2 - 3 } \cline { 5 - 6 } & 2011 & 2012 & & 2011 & 2012 \\
\hline 7 & $0.0 \mathrm{~b}$ & $0.0 \mathrm{~b}$ & & $0.0 \mathrm{~b}$ & $0.4 \mathrm{a}$ \\
10 & $0.0 \mathrm{c}$ & $0.5 \mathrm{c}$ & $7.5 \mathrm{~b}$ & $25.0 \mathrm{a}$ \\
13 & $0.3 \mathrm{~d}$ & $4.7 \mathrm{c}$ & & $44.4 \mathrm{~b}$ & $52.3 \mathrm{a}$ \\
16 & $2.1 \mathrm{~d}$ & $13.7 \mathrm{c}$ & & $53.5 \mathrm{~b}$ & $62.7 \mathrm{a}$ \\
20 & $4.7 \mathrm{~d}$ & $26.5 \mathrm{c}$ & & $59.8 \mathrm{~b}$ & $69.9 \mathrm{a}$ \\
24 & $6.2 \mathrm{~d}$ & $35.5 \mathrm{c}$ & $64.5 \mathrm{~b}$ & $72.4 \mathrm{a}$ \\
28 & $9.1 \mathrm{c}$ & $43.5 \mathrm{~b}$ & $66.2 \mathrm{a}$ & $73.1 \mathrm{a}$ \\
\hline
\end{tabular}

means within each row with the same letters do not differ significantly according to the Tukey test $(p=0.01)$ 


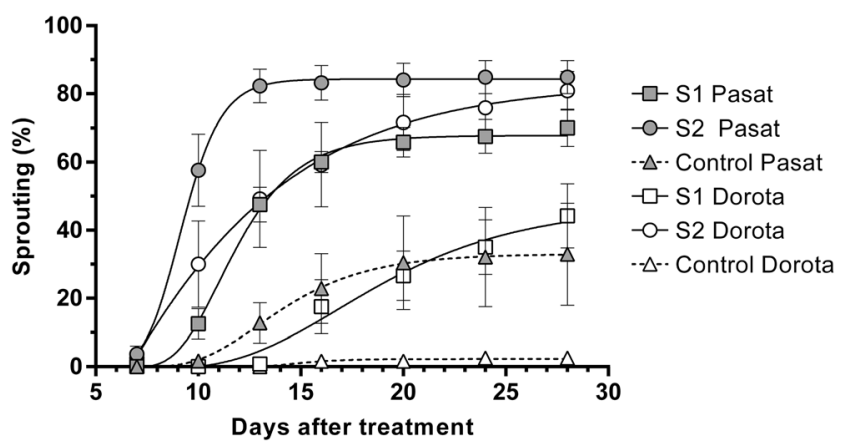

Fig. 1 The rate of sprouting of potato eye-plugs for cv. Dorota and Pasat after soaking in different reagents. $\mathrm{S} 1-$ standard $1\left(\mathrm{GA}_{3}+\right.$ kinetin +15 min soaking); $\mathrm{S} 2$ - standard $2\left(\mathrm{GA}_{3}+\right.$ thiourea $+\mathrm{B}-\mathrm{Nine} 85 \mathrm{SG}+$ 15 min time soaking); Control - demineralized water +15 min soaking. The cuttings were grown for 28 days in the dark at $21 \pm 1{ }^{\circ} \mathrm{C}$ and $85 \pm 5 \%$ RH. The error bars indicate the standard error of the mean. Data represents averages from independent replicates from 2 years, with 3 replicates each year

during the entire time of the experiment (up to 28 dat.), while in the cv. Pasat, significant differences were only observed up to 13 dat. After that time, the number of sprouted cuttings was similar, regardless of the duration of soaking.

\section{Comparison of Mixtures Composed of Ethanol and Phytohormones with Standards 1 and 2}

Next, we tested the effect of (i) ethanol, (ii) ethanol combined with $\mathrm{GA}_{3}$ or kinetin and (iii) ethanol combined with $\mathrm{GA}_{3}$ and kinetin on sprouting rate on both Dorota (Fig. 2) and Pasat cultivars (Fig. 3) when compared to standard 1 and 2 treatments. Comparing to control, ethanol treatment, in all combinations, induced sprouting. However, the rate of sprouting and its efficacy varied. The differences in cultivar responses were significant, thus we report both cultivar results separately.

In cv. Dorota, ethanol alone induced dose-dependent sprouting but the rate of sprouting was very low. At 28 dat. The number of sprouts was 8-fold and 4-fold lower than that

Table 4 Effect of ethyl alcohol on the sprouting and subsequent emergence of potato tuber cuttings after 28 days of observation, expressed as an average percentage of sprouted cuttings

\begin{tabular}{llcc}
\hline Observations & Ethyl alcohol [\%] & cv. Dorota & cv. Pasat \\
\hline Sprouting & 0.5 & $17.2 \mathrm{a}$ & $65.4 \mathrm{~b}$ \\
& 1.0 & $27.4 \mathrm{a}$ & $66.4 \mathrm{~b}$ \\
& 2.0 & $21.6 \mathrm{a}$ & $73.1 \mathrm{ab}$ \\
Emergence & 4.0 & $26.4 \mathrm{a}$ & $76.7 \mathrm{a}$ \\
& 0.5 & $8.7 \mathrm{a}$ & $7.4 \mathrm{a}$ \\
& 1.0 & $13.9 \mathrm{a}$ & $6.2 \mathrm{a}$ \\
& 2.0 & $15.4 \mathrm{a}$ & $10.9 \mathrm{a}$ \\
& 4.0 & $16.4 \mathrm{a}$ & $10.8 \mathrm{a}$ \\
\hline
\end{tabular}

means within each column for sprouting or emergence with the same letters do not differ significantly according to the Tukey test $(p=0.01)$
Table 5 Effect of gibberellin on the sprouting and subsequent emergence of potato tuber cuttings after 28 days of observation, expressed as an average percentage of the sprouted cuttings

\begin{tabular}{llrr}
\hline Observations & Gibberellin & cv. Dorota & cv. Pasat \\
\hline Sprouting & no & $7.5 \mathrm{~b}$ & $59.3 \mathrm{~b}$ \\
& yes & $43.8 \mathrm{a}$ & $80.6 \mathrm{a}$ \\
Emergence & no & $1.9 \mathrm{~b}$ & $3.3 \mathrm{~b}$ \\
& yes & $35.0 \mathrm{a}$ & $16.4 \mathrm{a}$ \\
\hline
\end{tabular}

means within each column for sprouting or emergence with the same letters do not differ significantly according to the Tukey test $(p=0.01)$

induced by standard 2 and standard 1, respectively (Fig. 2a). The addition of either $\mathrm{GA}_{3}$ (Fig. 2b) or kinetin (Fig. 2c) had a profound impact on the efficacy of the ethanol treatment. The sprouting rate and the final number of sprouts were comparable to the standard 1 treatment. The presence of $\mathrm{GA}_{3}$ or kinetin lowered the dose dependency for all ethanol concentrations, except the lowest one. When ethanol was combined with both $\mathrm{GA}_{3}$ and kinetin, the ethanol dose dependence was observed again (Fig. 2d). In the presence of both hormones the lowest tested ethanol concentration $(0.5 \%)$ was almost as effective as standard 2, and 1-2\% ethanol induced sprouting rate, which was intermediate between standard 1 and 2 . The highest tested ethanol concentration (4\%) in the presence of $\mathrm{GA}_{3}$ and kinetin increased the final number of sprouts (at 28 dat.) to the level of standard 2 (Fig. 2d). The rate of sprouting induced by $4 \%$ ethanol supplemented with both hormones was only slightly lower than that of standard 2 and highest among all ethanol treatments (Fig. 2d).

Cultivar Pasat reacted to control treatment (soaking in water) significantly stronger than cv. Dorota (Fig. 2a) with first sprouts formed at 13 dat. And $20 \%$ of eye-plugs sprouted at 28 dat. (Fig. 3a). For all non-control treatments, the first sprouts were observed at 10 dat. The response to all ethanol concentrations was significantly stronger than for cv. Dorota and was dose-dependent, but to lower extent than in the case of cv. Dorota (compare Fig. 3a vs. 2a). Ethanol at higher concentrations $(2-4 \%)$ induced a response similar to that of standard 1 (Fig. 3a). The addition of $\mathrm{GA}_{3}$ had a tremendous effect on

Table 6 Effect of kinetin on the sprouting and subsequent emergence of potato tuber cuttings after 28 days of observation, expressed as a mean percentage of sprouted cuttings

\begin{tabular}{llll}
\hline Observation & Kinetin & cv. Dorota & cv. Pasat \\
\hline Sprouting & no & $18.8 \mathrm{~b}$ & $74.6 \mathrm{a}$ \\
& yes & $27.5 \mathrm{a}$ & $66.7 \mathrm{~b}$ \\
Emergence & no & $10.1 \mathrm{~b}$ & $11.1 \mathrm{a}$ \\
& yes & $17.2 \mathrm{a}$ & $6.6 \mathrm{~b}$ \\
\hline
\end{tabular}

means within each column for sprouting or emergence with the same letters do not differ significantly according to the Tukey test $(p=0.01)$ 
Table 7 Effect of treatment duration (average from all assessed combinations) on the sprouting of potato tuber cuttings over 28 days of observation, expressed as an average percentage of sprouted cuttings

\begin{tabular}{lccccr}
\hline Observation day & \multicolumn{2}{l}{ cv. Dorota } & & \multicolumn{2}{c}{ cv. Pasat } \\
\cline { 2 - 3 } \cline { 5 - 6 } & $15 \mathrm{~min}$ & $30 \mathrm{~min}$ & & $15 \mathrm{~min}$ & $30 \mathrm{~min}$ \\
\hline 7 & $0.0 \mathrm{a}$ & $0.0 \mathrm{a}$ & & $0.0 \mathrm{~b}$ & $0.4 \mathrm{a}$ \\
10 & $0.0 \mathrm{~b}$ & $0.2 \mathrm{a}$ & & $10.7 \mathrm{~b}$ & $20.0 \mathrm{a}$ \\
13 & $0.7 \mathrm{~b}$ & $2.8 \mathrm{a}$ & $43.9 \mathrm{~b}$ & $53.4 \mathrm{a}$ \\
16 & $3.5 \mathrm{~b}$ & $8.9 \mathrm{a}$ & $57.1 \mathrm{a}$ & $60.1 \mathrm{a}$ \\
20 & $9.7 \mathrm{~b}$ & $16.2 \mathrm{a}$ & $66.5 \mathrm{a}$ & $64.7 \mathrm{a}$ \\
24 & $13.2 \mathrm{~b}$ & $22.2 \mathrm{a}$ & $70.0 \mathrm{a}$ & $68.7 \mathrm{a}$ \\
28 & $18.9 \mathrm{~b}$ & $27.4 \mathrm{a}$ & $71.1 \mathrm{a}$ & $69.9 \mathrm{a}$ \\
\hline
\end{tabular}

means within each row for each cultivar with the same letters do not differ significantly according to the Tukey test $(p=0.01)$

sprouting rate (Fig. 3b). In presence of $\mathrm{GA}_{3}$, all ethanol doses worked better than standard 1 and induced rate of sprouting close $(0.5-2 \%)$ or higher $(4 \%)$ than that induced by standard 2 (Fig. 3b). The combination of $\mathrm{GA}_{3}$ with $4 \%$ ethanol induced $80 \%$ of eye-plugs to sprout 13 dat. And $95.5 \%$ of eye-plugs was sprouted 28 dat. (Fig. 3b). Kinetin exhibited a slight negative effect on ethanol ability to induce sprouting (compare Fig. 3c to a) and to the boost of this activity by $\mathrm{GA}_{3}$ (Fig. 3d). However, the treatment was still very efficient and did not differ significantly from the combination of ethanol with $\mathrm{GA}_{3}$ alone (Compare Fig. 3d to b). The combination of both hormones with $4 \%$ ethanol stimulated the sprout growth at 24 and 28 dat. to the same level as standard 2 (Fig. 3d)

\section{Correlation between Sprouting and Subsequent Plant Emergence}

In experiments described above the efficacy of plant emergence was consistently lower than that of sprouting, regardless of the agent used to breake dormancy (Tables 4-6, emergence). Statistical analysis, performed on combined data indicated that correlation increased with each additional day following planting of cuttings. At the end of growing period, it was strong for cv. Dorota but relatively weak for cv. Pasat (Table 8). In the case of cv. Pasat, sprouts started to rot before planting, which probably limited subsequent emergence. Thus, results for this cultivar are inconclusive. Therefore, the effect of the composition of the treatment solution on the correlation between the number of sprouts and the number of plants was tested for cv. Dorota only. Among tested treatments, the highest convergences were found for Standard 2 with $82.3 \%$ of sprouted eye-plugs at 28 dat. And $93.2 \%$ of emerged plants after subsequent 28 days of growth in greenhouse. Similar efficacy was observed for $4 \%$ of ethanol + $\mathrm{GA}_{3}+$ kinetin +30 min time soaking with $95 \%$ of sprouted eye-plugs and $63.3 \%$ of emerged plants (Fig. 4).

\section{Determination of ABA Concentration}

$\mathrm{ABA}$ is considered to be the principal dormancy inducing and maintaining agent (Suttle 1998). Therefore, to more fully understand the physiological basis for treatments with the highest dormancy terminating activity, the effects of standard 1 , standard 2 and mixtures of ethanol with GA and kinetin on
Fig. 2 Effect of ethanol alone (a) or in combination with $\mathrm{GA}_{3}$ (b), kinetin (c) or both (d) on the rate of sprouting of dormant eye-plugs of cv. Dorota. The cuttings were immersed in ethanol solutions for $30 \mathrm{~min}$ and grown for 28 days in the dark at $21 \pm 1{ }^{\circ} \mathrm{C}$ and $85 \pm 5 \%$ RH. Control - demineralized water +15 -min soaking. The error bars indicate the standard error of the mean. Data represents averages from independent replicates from 2 years, with 3 replicates each year
A

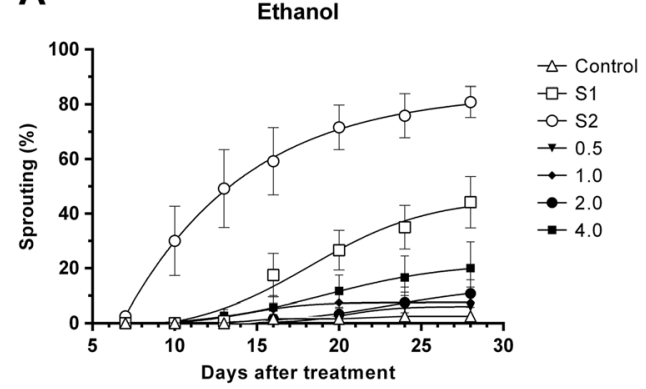

C

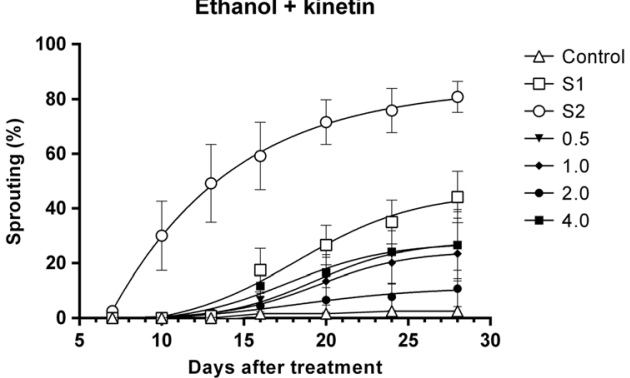

B

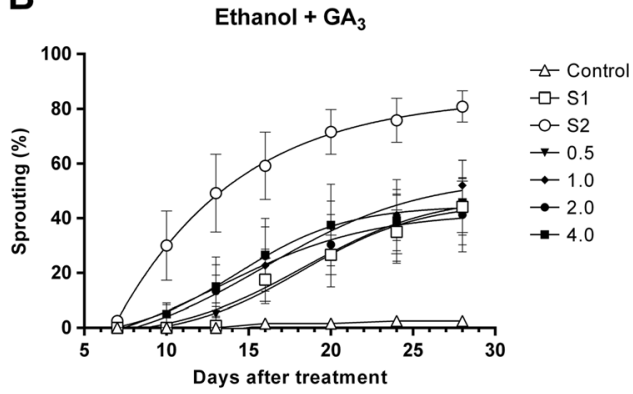

D

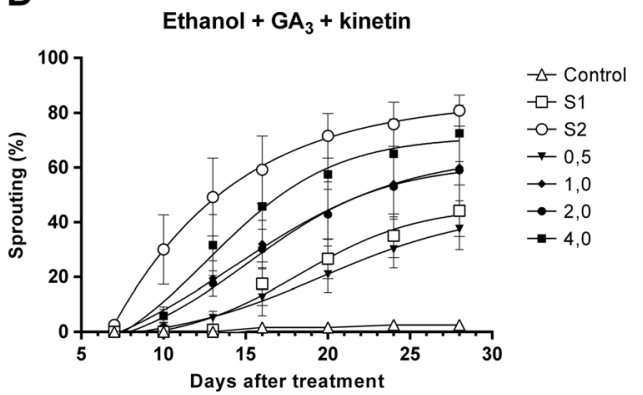


A

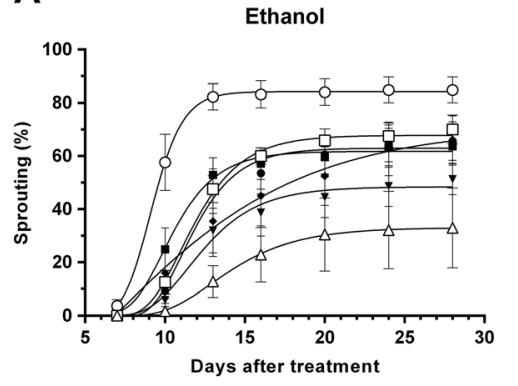

C

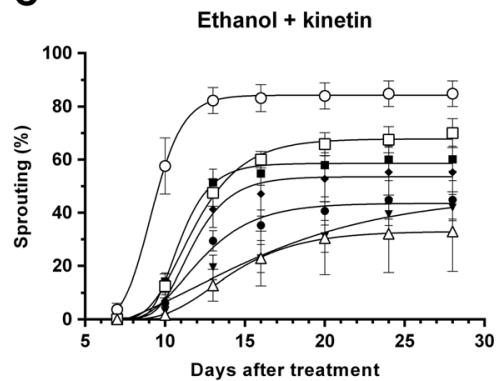

Fig. 3 Effect of ethanol alone (a) or in combination with $\mathrm{GA}_{3}(\mathbf{b})$, kinetin (c) or both (d) on the rate of sprouting of dormant eye-plugs of cv. Pasat. The cuttings were immersed in ethanol solutions for $30 \mathrm{~min}$ and grown for 28 days in the dark at $21 \pm 1{ }^{\circ} \mathrm{C}$ and $85 \pm 5 \% \mathrm{RH}$. Control -

the endogenous levels of $\mathrm{ABA}$ were measured immediately after soaking and 28 dat. A significant, three- (cv. Dorota) and two-fold (cv. Pasat) reductions in ABA concentrations were observed after treatment with standard 2 (Table 9). Also, control treatment (soaking eye-plugs in water) lowered significantly the ABA level in cv. Dorota but to a lesser extent than standard 2. In contrast, control had no impact on ABA level in cv. Pasat. Treatments with standard 1 or with the mixtures of ethanol with hormones had no significant impact on the level of ABA in both cultivars.

Table 8 The Pearson correlation coefficients between the number of sprouted tuber cuttings and the number of grown plants $(p=0.01)$

\begin{tabular}{llc}
\hline Days of observation & \multicolumn{2}{l}{ Correlation coefficients } \\
\cline { 2 - 3 } & cv. Dorota & cv. Pasat \\
\hline S7 - P7 & -0.04 & -0.06 \\
S10 - P10 & 0.38 & 0.31 \\
S13 - P13 & 0.65 & 0.39 \\
S16- P16 & 0.74 & 0.42 \\
S20 - P20 & 0.78 & 0.46 \\
S24 - P24 & 0.79 & 0.43 \\
S28 - P28 & 0.80 & 0.44 \\
\hline
\end{tabular}

${ }^{\dagger} S$ - the number of sprouted tuber cuttings on a particular day after treatment, $P$ - the number of plants on a particular day after planting of sprouted tuber cuttings.
B

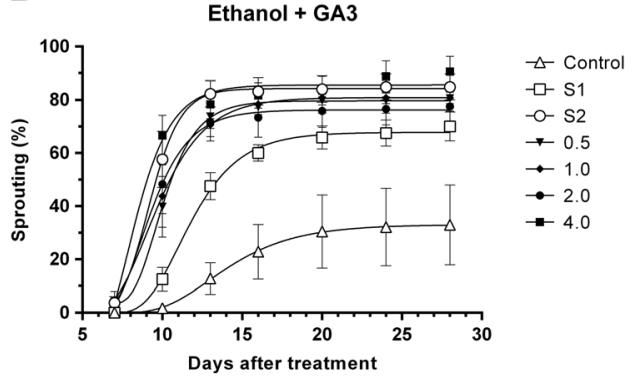

D

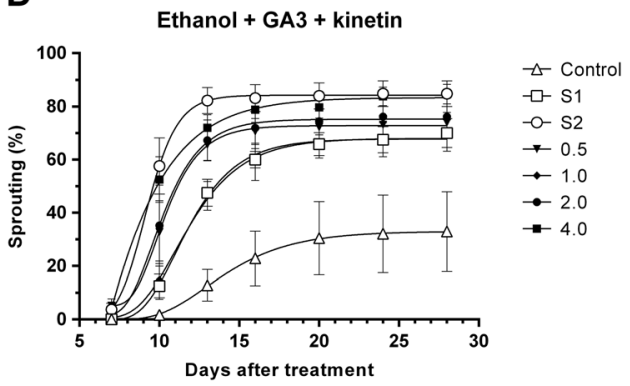

demineralized water +15 -min soaking. The error bars indicate the standard error of the mean. Data represents averages from independent replicates from 2 years, with 3 replicates each year

\section{Discussion}

In potato industry, long dormancy results in better quality preservation during tuber storage. However, prolonged and unregulated dormancy is often undesirable in breeding or in seed tubers production, especially when rapid cycling of potato generations is needed or when health status of seed tubers has to be certified. While dormancy release has been

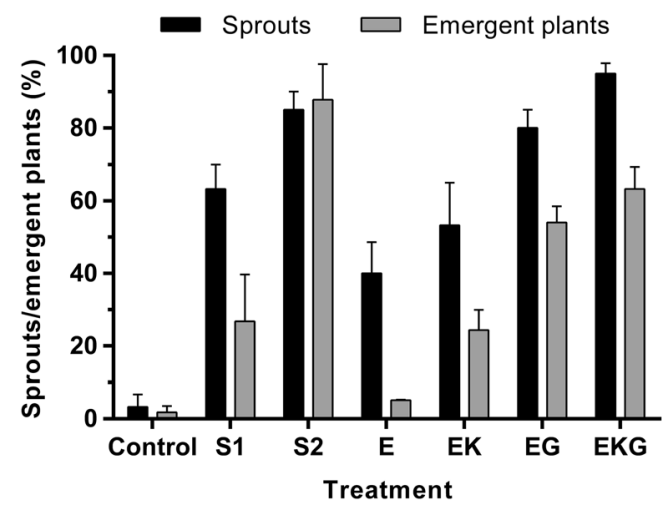

Fig. 4 Effect of different treatments on sprouting and subsequent plant emergence of cv. Dorota. Control - demineralized water +15 -min soaking, S1 - standard 1; S2 - standard 2, E - 30 min soaking of eyeplugs in $4 \%$ ethanol, EK -30 min soaking in $4 \%$ ethanol + kinetin, EKG -30 min soaking in $4 \%$ ethanol + kinetin $+\mathrm{GA}_{3}$. The cuttings were grown for 28 days in the dark at $21 \pm 1{ }^{\circ} \mathrm{C}$ and $85 \pm 5 \% \mathrm{RH}$ (Sprouts) and next were cultivated for 28 days in the green-house (Emergent plants). The error bars indicate the standard error of the mean. Data represents one year (2012) averages from 3 independent replicates 
Table 9 ABA content in potato tubers cuttings cv. Pasat and Dorota after application of selected dormancy-breaking agents. Values are means in $\mathrm{ng} \cdot \mathrm{g}$ $\mathrm{FW}^{-1} \pm \mathrm{SE}(n=9)$

\begin{tabular}{|c|c|c|c|c|}
\hline \multirow[t]{2}{*}{ Treatment } & \multicolumn{2}{|l|}{ cv. Pasat } & \multicolumn{2}{|l|}{ cv. Dorota } \\
\hline & $\begin{array}{l}\text { Immediately after } \\
\text { soaking }\end{array}$ & $\begin{array}{l}28 \text { days after } \\
\text { treatment }\end{array}$ & $\begin{array}{l}\text { Immediately after } \\
\text { soaking }\end{array}$ & $\begin{array}{l}28 \text { days after } \\
\text { treatment }\end{array}$ \\
\hline Control (deionized water) & $174 \pm 8$ & $161 \pm 13$ & $175 \pm 27$ & $101 \pm 9 * *$ \\
\hline Standard 1 & $123 \pm 19$ & $124 \pm 19$ & $164 \pm 12$ & $138 \pm 14$ \\
\hline Standard 2 & $180 \pm 41$ & $88 \pm 20^{*}$ & $121 \pm 17$ & $38 \pm 7 * *$ \\
\hline $\begin{array}{c}2 \% \text { ethanol }+\mathrm{GA}+ \\
\text { kinetin }(15 \mathrm{~min})\end{array}$ & $141 \pm 33$ & $179 \pm 32$ & $158 \pm 16$ & $211 \pm 56$ \\
\hline $\begin{array}{c}4 \% \text { ethanol }+\mathrm{GA}+ \\
\text { kinetin }(30 \mathrm{~min})\end{array}$ & $208 \pm 31$ & $207 \pm 22$ & $297 \pm 21$ & $305 \pm 32$ \\
\hline
\end{tabular}

$*$ ** indicate significance from immediately after soaking controls, $p<0.05$ and 0.01 , respectively. extensively studied (Suttle 2004b; Suttle 2007; Sonnewald and Sonnewald 2014), only a few practical and environment-friendly protocols can be found in the literature (Bruinsma et al. 1967; Jansky and Hamernik 2015).

In this study we compared efficacy of two established protocols of dormancy breaking. Both are based on short dipping of excised potato eyes in aqueous solution of $\mathrm{GA}_{3}$ combined either with kinetin (standard 1) or with thiourea and daminozide (standard 2). Standard 1 is used by Polish Plant Health and Seed Inspection Services for breaking dormancy during certification of seed tubers by grow-out test and standard 2 has been used since years for the same purpose in our Department, but comparison of protocols was lacking.

The depth and duration of dormancy are mainly determined by potato genotype (Bruinsma et al. 1967; Struik and Wiersema 1999; Bamberg 2010, 2014; Külen et al. 2011; Wróbel and Robak 2014). This may influence the response of cultivars to artificial dormancy breaking treatment. Indeed, Polish Plant Health and Seed Inspection Services often reported that some cultivars did not sprout, when treatment was done shortly after harvest. To solve this problem, response of different cultivars to dormancy terminating treatment was investigated in relation to the duration of tuber storage (Wróbel 2008; Wróbel and Robak 2011, 2014). In these studies, cultivars were grouped according to their ability to sprout after artificial dormancy termination. Most cultivars sprouted directly after harvest but some cultivars required 5 or 10 weeks storage before treatment was effective (Wróbel and Robak 2014). Thus, to compare protocols, we used two potato genotypes representing these two groups with moderate (cv Pasat) and long dormancy (cv Dorota), lasting respectively 5 (Wróbel 2008) and 10 weeks (Wróbel and Robak 2011). While these genotypes are not widely grown, they are good models of cultivars exhibiting moderate and long dormancy. For the same purpose, tubers were treated on the second day after harvest, when dormancy intensity is high (Struik and Wiersema 1999). In this work, we confirmed that cv. Dorota has deeper dormancy than cv. Pasat (Table 1) and that this difference did not depend on the growing season (Table 2).
However, the growing season significantly impacted the relative depth of dormancy of both cultivars. In 2012 the tuber dormancy was much easier to break than in 2011, regardless of the cultivar (Table 2). It was reported that dry and warm weather during growing season shortened the dormancy duration (Zarzyńska 2004, 2010; Rykaczewska 2015) while high humidity had opposite effect (Zarzyńska 2004, 2010). However, weather conditions during the growing seasons of 2011 and 2012 were very similar. Thus probably other unknown factors influenced the rate of tuber initiation and maturing.

Using cv. Pasat and cv. Dorota as a models of moderate and long dormancy genotypes, we showed here, that standard 2 had higher efficacy than standard 1 in promoting dormancy termination, regardless of the cultivar (Fig. 1). Moreover, while potato genotypes influenced significantly the rate of sprouting in expected manner (higher for cv. Pasat than for cv. Dorota), the effective artificial dormancy termination, defined as $80 \%$ of $2 \mathrm{~mm}$ sprouts, was achieved for both cultivars only with standard 2 treatment (Fig. 1). Since both, standard 1 and standard 2, contain the same concentration of $\mathrm{GA}_{3}$, higher efficacy of the standard 2 treatment than standard 1 , had to result from additional action of daminozide and/or thiourea. First compound is a growth regulator, mainly responsible for shortening of internodes. It was used to suppress negative effects of $\mathrm{GA}_{3}$ on development of sprouts and plants after artificial dormancy termination with $\mathrm{GA}_{3}$ (Bruinsma et al. 1967). Interestingly, thiourea is known to terminate dormancy of cultivars, which are weakly dormant or which are close to the end of their dormancy period (Struik and Wiersema 1999). Furthermore, treatment with thiourea terminated dormancy of minitubers, accelerated plant emergence, had positive impact on the number and height of stems, and increased tuber yield (Hosseini et al. 2011; Germchi et al. 2011; Mani et al. 2013a, 2013 b). It was proposed, that thiourea acts as a catalase inhibitor and leads to increase in the concentration of hydrogen peroxide, which may play a crucial role in the mechanism of dormancy termination (Bajji et al. 2007; Mani et al. 2013a, $2013 \mathrm{~b}$ ). Thus, in standard 2 protocol, synergistic action of 
$\mathrm{GA}_{3}$ and thiourea could cause high efficacy of dormancy termination (Fig. 1), while thiourea together with daminozide could have positive impact on subsequent plant emergence (Fig. 4).

Recently it was reported that ethanol can rapidly terminate dormancy in in vitro-cultured growing and maturing tubers (Claassens et al. 2005). However, it is unknown, if dormancy of field grown tubers can be also broken by ethanol. Thus, we investigated the effect of ethanol alone or in combination with $\mathrm{GA}_{3}$ and/or kinetin on dormancy release and sprouting of potato tubers and compared the ethanol effect to standard 1 and 2. Ethanol increased the number of sprouted cuttings in comparison to the control, however the number of sprouting was variable and for most combinations significantly lower than that of standard 2 (Figs. 2 and 3). Dormancy termination was enhanced by the addition of $\mathrm{GA}_{3}$ (Table 5) and kinetin (Table 6) to the ethanol, and was depended on the genotype with higher effect on less dormant cultivar (Table 4). Also increase of ethanol concentration had positive impact on sprouting (Table 4). On the basis of the obtained results (Table 4), it can be assumed that further increase in the alcohol concentration would further enhance sprouting. It is possible that in this work we did not treat tuber tissues with an effective ethanol concentration. Claassens et al. (2005) showed that $0.5 \%$ ethanol was effective, however in that work, ethanol has been added to the growth medium, and minitubers were uptaking it by stem through entire duration of the experiment. In our study, the time of ethanol uptake by eye-plugs was limited to 15 or $30 \mathrm{~min}$ with longer time being more effective (Table 7). This suggests, that ethanol uptake by tuber tissue is slower than that of $\mathrm{GA}_{3}$, which seemed to be effective regardless of the soaking duration (Bruinsma et al. 1967; Jansky and Hamernik 2015). Most studies (Alexopoulos et al. 2008; Salimi et al. 2010; Mani et al. 2013a, 2013b; Bajji et al. 2007; Hosseini et al. 2011) used considerably longer treatment periods than we employed, up to several hours, which may have significantly improved the effectiveness of treatments. However, the routine use of such long durations, e.g. during the official post-harvest inspection assessment of seed potato lots, may be impractical.

Dipping eye-plugs in ethanol alone or in combination with $\mathrm{GA}_{3}$ stimulated sprouting in the dose and cultivar dependent manner (Table 4, Figs. 2 and 3). The strongest stimulation was obtained using $4 \%$ alcohol supplemented with $\mathrm{GA}_{3}$ and kinetin for cv. Dorota (Fig. 2d) or $4 \%$ alcohol with $\mathrm{GA}_{3}$ for cv. Pasat (Fig. 3b). However, for this cultivar treatment with $4 \%$ ethanol including $\mathrm{GA}_{3}$ and kinetin was almost as effective (Fig. 3d). Efficacies of these ethanol combinations were similar to efficacy of standard 2 and resulted in $80 \%$ of eye-plugs sprouting 28 days after treatment (Figs. 2 and 3). Treatments with $4 \%$ ethanol supplemented with kinetin alone, were much less efficient than standard 2 for both cultivars, slightly less efficient than standard 1 for cv. Dorota (Fig. 2b) and similar to the efficacy of standard 1 for cv. Pasat (Fig. 3b). Thus, kinetin was not particularly beneficial for the artificial dormancy termination. Results reported by other researchers regarding the participation of cytokines in dormancy break were also inconsistent. Suttle (2004b) showed that endogenous cytokinins are the principal factor leading to the loss of tuber dormancy. Treatment with exogenous cytokinins could break dormancy, however at later stages of storage, when dormancy was weaker (Turnbull and Hanke 1985a, 1985b; Suttle 2004b). The initial period of resistance of tubers during early storage to artificial dormancy break was reduced but not eliminated by treatment with synthetic phenylurea and nitroguanidine cytokinins (Suttle 2008).

Analysis of the results in this work revealed that the greatest effect on breaking dormancy was through the use of $\mathrm{GA}_{3}$. Regardless of the cultivar, $\mathrm{GA}_{3}$ significantly increased the number of sprouted eye-plugs (Table. 5) and the rate of sprouting (Figs. $2 \mathrm{~b}$ and $3 \mathrm{~b}$ ). This was most evident for $\mathrm{cv}$. Dorota, which was the most difficult to break. However, to fully overcome dormancy of this cultivar, additional action of ethanol and kinetin (Fig. 2b) or thiourea and daminozide (Fig. 1) was needed. The effectiveness of exogenous gibberellins in dormancy breaking, as applied both in the form of foliar sprays at the end of the growing season (van Ittersum and Scholte 1993) and on the tubers after harvesting, has been reported previously (Rappaport et al. 1957; Bruinsma et al. 1967; Gregorius et al. 2008; Salimi et al. 2010). Dogonadze et al. (2000) found that gibberellins decreased the content of ABA and ethylene in buds. However, results obtained by Suttle (2004a) and Hartmann et al. (2011) supported the main role for endogenous cytokinins in potato tuber dormancy release and were consistent with a role for endogenous GAs in regulating subsequent sprout growth.

It may happen, that deeply dormant tubers form sprouts after treatment, but further sprout growth is inhibited (Struik and Wiersema 1999). Thus emergence of offspring plants can also be used to measure effectiveness of treatment. We observed significant influence of the treatment composition on plant emergence. Ethanol alone induced sprouting, but to support subsequent plant emergence required addition of kinetin or $\mathrm{GA}_{3}$ (Fig. 4). As Table 5 indicates, $\mathrm{GA}_{3}$ was essential for the subsequent growth of seedlings. However, effect of this phytohormone was strongly enhanced by thiourea and daminozide, since the most efficient plant emergence was observed after standard 2 treatment (Fig. 4). This effect was, largely a consequence of more efficient induction of sprouting by this treatment and could be related to growth regulatory action of both compounds, as discussed above.

Claassens et al. (2005) proposed that ethanol acts through alcohol dehydrogenase increasing the NADH concentration, which changes the ratio $\mathrm{NADH} /\left(\mathrm{NADH}+\mathrm{NAD}^{+}\right)$, called catabolic redox charge. Rylski et al. (1974) found that ethylene, a derivative of ethyl alcohol, also effectively reduced 
dormancy of potato tubers, however, when used over a period of more than three days, exerted an opposite effect. The authors also established that ethylene had a dual action on the tubers: it reduced the dormancy time and inhibited elongation of sprouts. Particularly effective in dormancy breaking was ethylene chlorhydrin, which resulted in $50 \%$ of tubers sprouting within 4 days of treatment, and $100 \%$ after 20 days. Similar results were obtained by Coleman (1998), who also showed that exogenous ethylene caused a reduction in $\mathrm{ABA}$ content. Ethylene is thought to play a critical role in the induction of tuber dormancy but was also reported to increase during onset of sprouting (Suttle 2007). Thus its role in dormancy is unclear (Suttle 2007; Sonnewald and Sonnewald 2014). More solid are data on the role of ABA in inducing and maintaining dormancy. During tuber formation, endogenous level of ABA was high in entire tuber but it was several times higher in dormant bud than in the surrounding storage tissue (Suttle 2007). During storage ABA gradually dropped, but rate of $\mathrm{ABA}$ lowering was higher in dormant bud (Suttle 2007). According to Claassens et al. (2005) ABA acts downstream of ethanol signaling, thus ethanol might lower the ABA concentration, but in their work, ABA level was not affected by ethanol. Similar result was reported by Suttle (2008), who observed that despite pronounced effect on sprouting, treatment with synthetic cytokinins had no effect on endogenous ABA level. In our study ethanol, kinetin and $\mathrm{GA}_{3}$ also did not influence ABA concentration in treated eyeplugs. However, standard 2 significantly lowered the ABA level, regardless of cultivar. This treatment contains thiourea, which was proposed to act by changing redox balance in the treated tissue (Bajji et al. 2007) and daminozide, which is known to inhibit endogenous GAs biosynthesis (Brown et al. 1997). Nevertheless, the lack of a clear reduction in the level of ABA, in most sprouting eye-plugs, may suggest that a reduction in the level of this hormone is not a prerequisite for their sprouting. Indeed, it was reported that although ABA positively regulates dormancy, there is no defined concentration threshold, which triggers bud break (Suttle 2007).

In conclusion, both $\mathrm{GA}_{3}$ and ethanol significantly reduced dormancy of potato tubers, while kinetin had lesser significance in this process. Treatment efficacy depended strongly on potato cultivars, with less dormant genotype showing more profound response. None of the treatments were as effective in dormancy breaking as standard 2, composed of $\mathrm{GA}_{3}$, thiourea, and daminozide (Fig. 1), although combination of $4 \%$ ethanol with $\mathrm{GA}_{3}$ and kinetin had a similar efficacy (Figs. 2 and 3). According to our knowledge, this is first report showing the dormancy terminating action of ethanol on field-grown seed tubers. Our results may encourage other seed certification programs and others requiring rapid tuber sprouting to examine the efficacy of standard 2 and ethanol $+\mathrm{GA}_{3}$ treatments, and fine-tune these treatments to their needs.
Acknowledgements The authors would like to thank Dr. Aurelie Rakotondrafara for critical review of the manuscript and Barbara Robak, Ela Okuniewicz and Marianna Kisiel, for their excellent technical work and involvement during the course of the research. This work was financially supported by National Science Centre, Poland, from grant $\mathrm{N}$ N310 722340 (to S.W.) and in part from grant 2016/21/B/NZ9/03573 (to K.T.).

Open Access This article is distributed under the terms of the Creative Commons Attribution 4.0 International License (http:// creativecommons.org/licenses/by/4.0/), which permits unrestricted use, distribution, and reproduction in any medium, provided you give appropriate credit to the original author(s) and the source, provide a link to the Creative Commons license, and indicate if changes were made.

\section{References}

Akoumianakis, K., C.M. Olympios, and H.C. Passam. 2000. Effect of "rindite" and bromoethane on germination, sprout emergence, number of sprouts and total yield of tubers of potato cv. Spunta. Advances in Horticultural Science 14: 33-35.

Alexopoulos, A.A., G. Aivalakis, K.A. Akoumianakis, and H.C. Passam. 2008. Effect of gibberellic acid on the duration of dormancy of potato tubers produced by plants derived from true potato seed. Postharvest Biology and Technology 49: 424-430.

Andrenelli, L., E. Palchetti, L. Malandrino, L. Espen, and V. Vecchio. 2005. In vitro study for dormancy in new potato clones. Proceedings from the $16^{\text {th }}$ Triennial Conference of the European Association for Potato Research, 785-787. Bilbao. July 17-22.

Bajji, M., M. M'Hamdi, F. Gastiny, J.A. Rojas-Beltran, and P. Du Jardin. 2007. Catalase inhibition accelerates dormancy release and sprouting in potato (Solanumtuberosum L.) tubers. Biotechnologie, Agronomie, Société et Environnement 11: 121-131.

Bamberg, J. 2010. Tuber dormancy lasting eight years in the wild potato Solanum jamesii. American Journal of Potato Research 87: 226228.

Bamberg, J. 2014. Observed limit of Solanum jamesii Tuber dormancy at 14 years. American Journal of Potato Research 91: 36.

Brown, G.S., K.H. Kawaide, Y.Y. Yang, W. Rademacher, and Y. Kamiya. 1997. Daminozide and prohexadione have similar modes of action as inhibitors of the late stages of gibberelin metabolism. Physiologia Plantarum 101: 309-313.

Bruinsma, J., A. Sinnema, D. Bakker, and J. Swart. 1967. The use of gibberellic acid (GA) and N-dimethylaminosuccinamic acid (B9) in the testing of seed potatoes for virus infection. European Potato Journal 10: 136-152.

Choudhuri, H.C., and S. Ghose. 1963. Effect of gibberellic acid on sprouting, growth of internodes, tuber shape and yield in different varieties of potatoes. European Potato Journal 6: 160-167.

Claassens, M.M.J., J. Verhees, L.H.W. van der Plas, A.R. van der Krol, and D. Vreugdenhil. 2005. Ethanol breaks dormancy of the potato tuber apical bud. Journal of Experimental Botany 56: 2515-2525.

Coleman, W.K. 1984. Large scale application of bromoethane for breaking potato tuber dormancy. American Potato Journal 61: 587-589.

Coleman, W.K. 1998. Carbon dioxide, oxygen and ethylene effects on potato tuber dormancy release and sprout growth. Annals of Botany 82: 21-27.

Dogonadze, M.Z., N.P. Korableva, T.A. Platonova, and G.L. Shaposhnikov. 2000. Effect of giberellin and auxin on the synthesis of abscisic acid and ethylene in buds of dormant and sprouting potato tuber. Applied Biochemistry and Microbiology 36: 507-509.

Germchi, S., F. GhannadiBehroozi, and S. Badri. 2011. Effect of thiourea on dormancy breaking and yield of potato (Solanum tuberosuml.) 
minitubers Marfona cv. In Greenhouse. International Conference on environmental and agriculture engineering IPCBEE vol. 15, 19-24. Singapore: IACSIT Press.

Gregorius, S., Ch. Olympiops, C. Akumianakis, and M. Geargiades. 2008. Effect of haulm application of gibberellic acid on the production and dormancy of minitubers of potato cv. Spunta. Proceedings from $17^{\text {th }}$ Triennial Conference of the European Association for Potato Research, 571-574. Brașov, România. July 6-10.

Hartmann, A., M. Senning, P. Hedden, U. Sonnewald, and S. Sonnewald. 2011. Reactivation of meristem activity and sprout growth in potato tubers require both cytokinin and gibberelin. Plant Physiology 155: 776-796.

Hemberg, T. 1970. The action of some Cytokinins on the rest-period and the content of acid growth-inhibiting substances in potato. Physiologia Plantarum 23: 850-858.

Hosseini, M.B., R.T. Afshari, and K. Salimi. 2011. Breaking dormancy of potato minitubers with thiourea. Potato Journal 38: 9-12.

Jansky, S., and A. Hamernik. 2015. Rapid cycling of potato tuber generations by overcoming dormancy. American Journal of Potato Research 92: 148-152.

Külen, O., C. Stushnoff, R.D. Davidson, and D.G. Holm. 2011. Gibberellic acid and ethephon alter potato minituber bud dormancy and improve seed tuber yield. American Journal of Potato Research 88: $167-174$

Mani, F., T. Bettaieb, N. Doudech, and C. Hannachi. 2013a. Effect of hydrogen peroxide and thiourea on dormancy breaking of microtubers and field-grown tubers of potato. African Crop Science Journal 21: 221-234.

Mani, F., T. Bettaieb, K. Zheni, N. Doudech, and C. Hannachi. 2013 b. Effect of thiourea on yield and quality of potato (Solanum tuberosum L.). Journal of Stress Physiology \& Biochemistry 9: 87-95.

Ranalli, P., M. Bizarri, L. Borghi, and M. Mari. 1994. Genotypic influence on in vitro induction, dormancy length, advancing age and agronomical performance of potato microtubers (Solanum tuberosum L.). Annals of Applied Biology 125: 161-172.

Rappaport, L., L.F. Lippert, and H. Timm. 1957. Sprouting, plant growth and tuber production as affected by chemical treatment of white potato seed pieces. American Potato Journal 34: 254-260.

Rykaczewska, K. 2015. The effect of high temperature and drought during growing season on potato (Solanum tuberosum L.) tuber rest period. (in Polish, with English abstract) Zeszyty Problemowe Postęów Nauk Rolniczych 581: 85-92.

Rylski, I., L. Rappaport, and H.K. Pratt. 1974. Dual effects of ethylene on potato dormancy and sprout growth. Plant Physiology 53: 658-662.

Salimi, Kh., R.T. Afshari, M.B. Hosseini, and P.C. Struik. 2010. Effects of gibberellic acid and carbon disulphide on sprouting of potato minitubers. Scientia Horticulturae 124: 14-18.

Sonnewald, S., and U. Sonnewald. 2014. Regulation of potato tuber sprouting. Planta 239: 27-38.
Struik, P.C., and S.G. Wiersema. 1999. Seed potato technology. Wageningen: Wageningen Academic Pub.

Suttle, J.C. 1998. Involvement of ethylene in potato microtuber dormancy. Plant Physiology 118: 843-848.

Suttle, J.C. 2004a. Involvement of endogenous gibberellins in potato tuber dormancy and early sprout growth: A critical assessment. Journal of Plant Physiology 161: 157-164.

Suttle, J.C. 2004b. Physiological regulation of potato tuber dormancy. American Journal of Potato Research 81: 253-262.

Suttle, J.C. 2007. Dormancy and sprouting. In Potato Biology and biotechnology: Advances and perspectives, ed. Dick Vreugdenhil, 287305. Amsterdam: Elsevier.

Suttle, J.C. 2008. Effects of synthetic phenylurea and nitroguanidine cytokinins on dormancy break and sprout growth in russet Burbank minitubers. American Journal of Potato Research 85: 121-128.

Turnbull, C.G.N., and D.E. Hanke. 1985a. The control of bud dormancy in potato tubers. Planta 165: 359-365.

Turnbull, C.G.N., and D.E. Hanke. 1985b. The control of bud dormancy in potato tubers. Measurement of the seasonal pattern of changing concentrations of zeatin-cytokinins. Planta 165: 366-376.

Van Ittersum, M.K., and K. Scholte. 1993. Shortening dormancy of seed potatoes by a haulm application of gibberellic acid and storage temperature regimes. American Potato Journal 70: 7-19.

Wilmowicz, E., J. Kęsy, and J. Kopcewicz. 2008. Ethylene and ABA interactions in the regulation of flower induction in Pharbitis nil. Journal of Plant Physiology 165: 1917-1928.

Wiltshire, J.J.J., and A.H. Cobb. 1996. A review of the physiology of potato tuber dormancy. Annals of Applied Biology 129: 553-569.

Wójcik, A.R., W. Gabriel, and W. Woźnica. 1976. Methods of transformation of percentagewise infection data in epidemiology of potato viruses. (in Polish, with English abstract) Biuletyn Instytutu Ziemniaka 17: 83-100.

Wróbel, S. 2008. Early dormancy breaking of tubers in fast virus diagnostic for new potato cultivars. (in Polish, with English abstract) Progress in Plant Protection 48: 552-555.

Wróbel, S., and B. Robak. 2009. Reakcja nowych odmian ziemniaka na przerywanie okresu spoczynku. (In Polish) Ziemniak Polski 1:1113.

Wróbel, S., and B. Robak. 2011. Response of new potato cultivars to dates of tubers breaking dormancy for the purposes of post harvest virus tests. (in Polish, with English abstract) Fragmenta Agronomica 28: $120-128$

Wróbel, S., and B. Robak. 2014. New potato cultivars characterized in regard to dormancy breaking of tubers. (in Polish, with English abstract) Biuletyn IHAR 272: 93-101.

Zarzyńska, K. 2004. The length of tuber dormancy period in new potato cultivars. (in Polish, with English abstract) Biuletyn IHAR 232: 5 14.

Zarzyńska, K. 2010. Odmianowe zróżnicowanie długości okresu spoczynku bulw ziemniaka. (In Polish) Ziemniak Polski 20: 14-17. 